\title{
The Borderline or The Impossibility of Producing a Negotiable Form in the Social Bond for the Return of the Censored
}

Lucie Cantin

Freudian School of Quebec and GIFRIC

How do we think the problem of the "Borderline" within psychoanalysis and the structural conception of psychic organization it proposes? As for the notion of a border between neurosis and psychosis that the case of the Borderline would simultaneously raise and call into question, we must rather recognize the failed experience of an internal limit in the subject with regard to the management of the censored that works and disorganizes the body in a jouissance that finds no path for its expression. The Borderline grapples with the work of the unbound drive, which is free and mobilized by unconscious and censored mental representations which fail to find both their mode of expression outside of the body and their meaning for the subject, as well as their negotiable form in the social space. In the absence of this space carved out in the social bond for the expression of the drive and of desire, the symptom and acting out inscribe and stage the censored within the public space, where its dramatization inevitably leads to a breakdown.

From the moment the psychoanalysis of Freud, followed by that of Lacan, defined three psychic structures, psychosis, neurosis and perversion, we left behind an evolutionary, linear and developmental perspective, one based on observation and phenomenology, in order to formulate a singular and exclusive logic (what mathematics would call 'discrete') for each one of these three psychic structures. The clinic however has not failed to interrogate these structural distinctions on the basis of a hybrid symptomatology which, from certain angles, seemed to suggest neurosis, while viewed from others, took the form of psychotic phenomena. Under the influence of a psychiatry increasingly focused on the treatment of the symptom, these "limitstates," [états-limites] as they have been called, have little by little been constituted as real, nosographically independent entities. The "Borderline" was born at the same time hysteria was disappearing from psychiatric diagnostic manuals, and owing to the psychotic appearance of the phenomena it presented, posed the question of the possibility of its treatment by psychoanalysis. Thus the Borderline joined the psychotic and the pervert in the field of clinical categories marking the limits or the failure of a certain type of psychoanalysis.

Our perspective is different, and it leads us to pose the question in a completely different way: how do we think the problem of the "Borderline" within psychoanalysis (and the structural conception of psychic organization it proposes), without quitting the field of neurosis, which is where, for us, the "Borderline" is situated? As for the notion of a border between neurosis and psychosis that the case of the Borderline would simultaneously raise and call into 
question, we must rather recognize the failed experience of an internal limit in the subject with regard to the management of the censored that works and disorganizes the body in a jouissance that finds no path for its expression. The Borderline grapples with the work of the unbound drive, which is free and mobilized by unconscious and censored mental representations, which fail to find both their mode of expression outside of the body and their meaning for the subject, as well as their negotiable form in the social space. In the absence of this space carved out in the social bond for the expression of the drive and of desire, the symptom and acting out inscribe and stage the censored in the public space, where its dramatization inevitably leads to a breakdown. For us, the problem of the Borderline is not that of the foreclosure of the Nameof-the-Father, which would make of him/her a psychotic, it is rather the problem of a phallic lapse or failure; that is, the impossibility for the subject to produce a negotiable form in the social bond for the return of the censored. But before we go any further, we must first lay some groundwork by taking into account a certain number of considerations, notably those concerning speech, language, and the phallus.

\section{The Body and Language}

Human language creates a trauma in each being, irrevocably severing him or her from the natural logic of life and from the reality accessible to the senses. This is no doubt the first lesson of psychoanalysis. Language produces a symbolic universe made up of representations of objects which exist only by way of words and the human desire that has given them birth. Justice, love, friendship, truth, beauty, art, ethics, democracy, one's country, one's nationality, good, evil, religion, God-in short, all that comprises the very foundations of human existence, as well as the importance one attaches to it, rests on a universe produced by language, a world of things that do not exist in the perceptible environment, but in the name of which, we act, love each other, and kill each other; a world in the name of which we live and will die. Language, for human being, thus creates a universe of mental objects that determine Meaning in a given society and time period. Language defines, as Willy Apollon emphasizes, the receivable, the obscene, and the censored, and thus establishes, through the positing of various ideals and prohibitions, the parameters that regulate and determine all of the possible relations, exchanges and discourses that can take place between individuals. Concerning the social bond, Lacan states, 
Je le désigne du terme de discours parce qu'il n'y a pas d'autre moyen de le désigner dès qu'on s'est aperçu que le lien social ne s'instaure que de s'ancrer dans la façon dont le langage se situe et s'imprime, se situe sur ce qui grouille, à savoir l'être parlant. (Encore 5I)

I designate it with the term "discourse," because there is no other way of designating it once one has realized that the social bond installs itself only by anchoring itself in the manner in which language situates itself and impresses itself, situates itself upon that which swarms, that is, the speaking being.

Language thus pre-exists the newborn infant. It is already there, having been built up over the ages. But prior to his entry into this language that structures reality and constitutes the social bond, the child encounters the Other. The Other, as yet undefined: the site of the signifier, Lacan would say, but as Willy Apollon makes clear, only to the extent that this signifier is conveyed by a Voice: a Voice that no longer has the harshness of a cry or of an animal's signal, but one that is full of a presence that it brings forth. A presence undefined, but whose effects in the body disrupt the beautiful order of the natural world to introduce into it a boundless Thing that creates a new energy, an energy henceforth in the service of the response and treatment of this effraction in the being. The presence of the phantom, of the undefined shadow, indistinct but active, which fills British literature and cinema, illustrates nicely the imaginary to which this initial experience of encounter with the Other of the Voice gives rise. Moreover, it is in light of this experience that we must understand what is at stake in Freud's concept of the primal fantasy. Like a myth of origins, the primal fantasy would give an account of the initial representation of the effraction that has cast the person into the universe of the signifier, the Other and the Voice: the universe of the audible, as Willy Apollon defines it. Initial representation of a thing that acts within the being at that moment of the child's life in which he is enclosed, immured, and delivered up to the effects of the Other and of the Voice, all while lacking the speech that would permit him to articulate his experience in the representations offered by language. The drive answers to the effraction produced by the boundless presence of the Other brought forth by the Voice, and consequently sets out in search of the object conveyed by this Voice of the Other. The access to language that occurs after this encounter with the Other comes to signify the necessary articulation of the child within a universe of 
Meaning, which projects him into a world completely different than the one-imaginary and real-that he experiences in his body, a body agitated by drives and inhabited by representations of things language cannot name. The human being is thus torn between two fields of representations, both of which, from the outset, have exiled him from a reality founded purely on the perception and consciousness of the environment. In this exile, the subject is faced with the particular task of having to reconcile these two worlds: on the one hand, that of the body traversed by mental representations of objects that do not exist in reality and which the energy of the drive invests in the fantasy; and on the other hand, the world of language, where the subject is confronted with the other in the social bond, with avatars of the demand and address of the other; where he is constrained to negotiate the satisfaction of his desires in keeping with the demands linked to the need for companionship and the necessities of life in society. The human being thus finds himself obliged to create his own articulation, his own way of managing these two "realities": the body and language.

In neurosis it is the paternal metaphor which articulates the child within the symbolic space, where the signifier of the Law restricts the fatal violence and the disorganizing effects of the effraction by the Other of the Voice. The Name-of-the-Father allows for the installation of the repression of this primordial experience by giving a face to the Voice; this not only ushers the Voice into the space of the visible, but bars the Other of the Voice by articulating it in the Law. The Name-of-the-Father introduces the child to another space, the symbolic space that constitutes and supports the social bond. This binding of the real effraction to the symbolic space makes possible the construction of a primal fantasy that presents the imaginary of the object introduced by the Voice and allows it to be regulated by the signifier of the Law. The psychotic who struggles with hallucinations, with these detached, errant and aggressive Voices whose effects he feels in his very flesh, gives us an idea of this experience of effraction by the Other of the Voice when it is not managed by the signifier of the Name-of-the-Father. In the absence of a fantasy marked out by the signifier of the Law, delusion develops as a mythical explanation, the production of an unbridled imaginary in an attempt to give a face and a name to the Other from whom the Voice originates, to identify what it requires of him.

The primal fantasy is thus a construction that produces an imaginary form for the Other (the site of the signifier) at the origin of the effraction and for the object of its jouissance. This imaginary, to the extent that it gives an account of an effraction, always stages -in psychosis, as 
in neurosis and perversion-an Other whose jouissance endangers the life or the integrity of the being. In psychosis, this fantasy, which implicitly determines the structure of the delusion from which it will be deduced in the process of the analytic cure, stages an Other whose demands leave no place whatsoever for the subject. This is the Other of the "cruel and ferocious superego," as Lacan puts it, with which the psychotic struggles for survival.

The primal fantasy constitutes an initial mode of treatment, a way of managing the foundational trauma of the subject. In constructing thus a "visibility" for the effraction, for its source as well as its object, the child creates a certain logic which will serve as the principle of the repetition. The primal fantasy is thus a sort of structural and formal matrix, whose logic determines the response of the drive and the contours of the mental representation that the drive invests in the irrepressible questing movement which is inscribed in the repetition.

The paternal metaphor thus makes it possible for the child to articulate the real with the symbolic, the body with language. This introduction of the child to symbolic space involves the entry into the social bond as it is presented and represented by the parent. Indeed, it is through the parental demand that the child has access to the ideals, prohibitions, norms and representations which structure social space, defining the conditions of coexistence and thus the limits of the subjective quest of an object for the drive in the fantasy. But the parent also provides the opportunity for the child to encounter something else, not only the something else of his own quest, but something other than the limits and the censorship posited by the cultural and social representations with which he must conform in order to enter into some form of companionship. Inevitably, the child encounters in the parental Other the objectcensored, and thus not represented in language_ — of demands stemming from parental dissatisfactions, demands linked to lacks and dissatisfactions which, because censored in the parent, pass into the act, the voice, the unsaid, and there take on all their Superego force. Received and interpreted as imperatives, demands of jouissance by the Other, they mobilize from then on the drive response of the child.

As a result, the drive is torn between the limitation and the censorship imposed on it by the symbolic in the social bond, the internal logic of an irrepressible quest for the object-cause of desire as it will have been determined and constructed by the primal fantasy, and the incontrovertible influence of the parental Superego, which diverts a part of the drive energy, putting it into the service of the Other's jouissance. The real of the internal experience the child 
has always lived in his body thus encounters at once the constraint of the symbolic and the diversion imposed by the Superego. From that point on the problem is twofold: how do we escape the injunction of the Superego, where the drive works for the Other? How do we instead mobilize the drive in the creation of a space of visibility in the social bond for the inadmissable mental representation that the drive of desire invests?

Once again the child's solution will involve the construction of a fantasy, what we call the fantasy of seduction. In the same way that the Name-of-the-Father allows the primal fantasy to be tempered by the signifier of the Law, the phallic signification produced by the Name-ofthe-Father makes possible the construction of the fantasy of seduction as a mode of treatment, as a way of managing the demands of the Superego. The fantasy of seduction, which Freud identifies in the solution proposed by Oedipus, produces the Ego as an ideal object in response to parental demands and exigencies, in the imaginary hope of thus freeing up the energy of the drive from the response to the Other in which it is locked up. But this solution, however necessary to the child, nevertheless remains that which will redouble the initial repression imposed by language. By producing himself as an object of the Other's desire, the child, in his fantasmatic construction, tempers the imperative demand of the Other but loses himself in it at the same time, falling into the fundamental error on which this identification rests. In this respect the production of the seduction fantasy is somewhat analogous to the structure of the Mirror Stage: both are based on error and profound mistake; and in both there is an alienation of the subject in the imaginary, where the Ego constructs itself by identifying with an imagined object of the Other's desire. The seduction fantasy, by producing the Ego as object, represses the Subject and its quest by introducing and nourishing the illusion of an object possible in reality for the drive of desire. But for this identification to function, for the Ego to be able to imagine itself and think of itself as an adequate object responding to the demands of the Superego, this identification must also be able to support itself through social demands. Perhaps it would be fairer to say that it is the articulation of the Superego with various social demands that makes possible, for the child, the solution of the seduction. In this respect, clinical experience confirms that the obsessive is the most successful in maintaining the illusion of the seduction. The obsessive's Ego is well-established in the certainty of having been the object of the Other's desire; through his scrupulous adherence to various social ideals and prohibitions he protects himself against guilt and against the work of the unbound drive within him. In the 
case of the hysteric, who experiences the insufficiency of language and the fragility of the barrier it erects against the return of the censored, the seduction fantasy is doomed, sooner or later, to reveal its failure, at once inevitable and structural. We will come back to this. For the time being we need to stress that, for structural reasons, the solution of seduction is doomed to fail for everyone. First, because the seduction fantasy leaves unresolved the work of the drive mobilized by the mental representation that, although censored and repressed, nevertheless remains active and in search of a means of expression that would succeed in any case; then, because the Ego, produced as object of the Other and articulated both with parental demands and with social ideals, encounters with the coming of adolescence the collapse of all that had previously served as a yardstick of its edification. That which-since the installation of the primacy of the phallus in childhood-framed the drive and gave it an acceptable form, linking it to the stakes of the seduction and the demand of the Other, crumbles with the emancipation of the adolescent, who opens himself up to the world. The adolescent accedes to the arbitrariness of all that is held up as ideal, including of course the justification of the parental demand. With this reappraisal of the very foundations of his being, and the deconstruction of the entire universe of meaning which proves to be that of the parental and social Other, the adolescent, henceforth profoundly unattached [celibataire], finds himself at a point beyond seduction, grappling with the unbound drive. Once again he is confronted with the original demand: how to articulate the body within language, how to articulate the real of the drive which acts upon both the being and the body with the symbolic space that constitutes society. Whereas the Name-of-the-Father had offered a ready-made solution, producing phallic signification within cultural prohibitions and ideals, it is now up to the subject himself to create his own solution; he will be charged with the task of producing a singular form, a signification for that which, inside of him, is un-presentable in the social bond. He will have to produce something that assumes the function of the phallus in order to manage the work of the drive, a drive that is henceforth severed from the bonds that attached it to the ideals and demands of the Other.

\section{The Phallus and Phallic Signification: the Question of a Limit to the Work of Jouissance}

"The phallus is a signifier," says Lacan. "It is the signifier intended to designate as a whole the effects of the signified, in that the signifier conditions them by its presence as a 
signifier" ("The signification of the phallus," Ecrits 285). This Lacanian formulation condenses the fundamental aspects at issue with the question of the phallus. First, it highlights the primacy, in the human, of the symbolic, of the signifier over the natural order of need whose subject is radically exiled by the existence of language. It designates moreover the double dimension introduced by the symbolic, namely, on the one hand, the rupture imposed by the signifier, the lack it introduces by substituting itself for the thing; and on the other hand, the effects of the signified, the phallic signification that the metaphor makes possible by the evocative power of the desire hollowed out by lack. It is within this framework that we must understand what Freud termed the "primacy of the phallus." Freud substituted this term for the "primacy of genitality," a concept he had originally developed to describe a moment in which the partial drives are assembled under and for the purpose of procreation. By substituting "primacy of the phallus" for "primacy of genitality," Freud shifted and clarified the stakes, as the latter term might have been understood as relating to physical maturation in a developmental perspective. As children of both genders are confronted by the phallus, Freud, by the use of this word, emphasizes the installation of the primacy of the symbolic order over autoerotic instinctual satisfaction, to the extent that this latter marks the true entry of the child into the universe of desire. For the boy, the primacy of the phallus signifies the loss of the penis as organ, the loss of the logic of the organ, and of the autoerotic jouissance attached to it. The installation of the phallus ushers the boy out of the field of the perceptible and visible and into the field of the effects of the signifier. The source of jouissance is not in the logic of the organ, but in the signifier that conditions it. The same goes for the girl: Oedipus forces her into an awareness of the effects of the signifier on the work of the drive in the body. A word from the Father, a signifier of his desire and love, installs the primacy of the order of the signifier through its structuring effects on the body, henceforth unified in an image conditioned by the signifier of the Other's desire. The primacy of the phallus is thus the primacy of the order of the signifier, the primacy of the audible where a representation for the object may be produced-an object that is no longer, from this point on, in the field of the perceptible. If the Name-of-the-Father, in articulating the Other of the Voice with the signifier of the Law, produces the Meaning which censors the hallucinatory mental representation in which the drive is nourished, the phallus, signifying the primacy of the signifier, creates a conduit for the drive that has been discounted by producing the possibility of a metaphor out of the field of the audible. The possibility of a 
metaphor, an evocation, a poetry that, by the signification it introduces, brings back that which has been rejected by Meaning.

The extraordinary level of infatuation generated by Stephanie Meyer's Twilight among young adolescent girls illustrates magnificently what is at stake in the phallus. Edward and Bella are adolescents and in love. Bella is human but Edward is a vampire. Thus he lives in the world of the Shadow, of the censored. Like all vampires, Edward drinks blood. And like all vampires, he can read others' thoughts; everyone's. . . except Bella's, the very person whose thoughts he wants to know. In accordance with a legend stating that they must give up human blood in order to make peace with a group of werewolves sharing the same territory, Edward and his clan have made a pact to become vegetarians, giving up human blood and thus allowing coexistence with the werewolves, beings both human and animal. Nevertheless, blood remains an object that triggers an instinctive response in them. Thus, however irresistibly attracted he is by the odor of Bella's blood, Edward must renounce touching her, or kissing her, for fear of being carried away and overwhelmed by his vampiric instinct, bringing about the death of his loved one by draining her of blood. Giving way to his desire for satisfaction would lead not only to the death of Bella and her transformation into a vampire, but would also break the peace pact on which the survival of the group rests. Consequently, the love relationship develops in a setting of restraint, of lack, of desire, of eroticism and of jouissance. They speak to each other, sleep together, caress each other with their fingertips, and brush lightly against each other, all of which ignites in each of them a hitherto unknown jouissance.

In the society adolescents grow up in today, at least in the West, where sexuality is equated with stereotypical, genital acts, muffled and often tainted with violence, and where desire is confused with sexual hunger and carnal satisfaction, it is not surprising that such a work has had so much success. The words of love the protagonists are constrained to create articulate with precision that which plays in their bodies with various signifiers; this results in jouissance and opens the being onto another space. The word springing up out of lack and from the desiring body offers at once a conduit, a signification, and a limit to the anxiety-provoking work of the unbound drive engaged in the eroticism roused by the adolescent's sexuality. The story of Bella and Edward is a good illustration of the double figure of the phallus, which consists of both the lack introduced by the order of the signifier, as well as the opening for the 
evocation of the censored that the signifier makes possible when it is bound to the body, transforming the drive into desire, and satisfaction into jouissance.

\section{The Borderline, or the Failed Installation of the Phallus}

The problem presented by the Borderline results from a failed installation of the phallus, which leaves the Borderline to grapple with the impossibility of creating a negotiable form in the social bond for the return of the censored and the work of the unbound drive in the body.

The failure of the phallus in the case of the Borderline marks the failed installation of the primacy of the symbolic over the logic of the drive. It is as if the censored mental representation and the drive that responds to it in the fantasy were monopolized, invaded by the demands of the Superego. The linking of the energy of the drive-under the cultural ideals and prohibitions the paternal function guarantees-both limits the demands of the Superego and leads to a loss on the part of the subject, a loss of satisfaction of the drive for which the phallus provides signification in symbolic space. For the phallic function to be effective for the child, that is, in order for him to be able to encounter and assume his own lack, the paternal phallus must refer the child to the realm of symbolic castration, to an impossible object. The child is not the object of the mother not because the object of her desire is the father, but rather because no other could be the object of desire, and because there exists no object for desire in perceptible reality.

Thus the loss must be linked to a structural lack in order for the limit to the demands resulting from censored parental dissatisfactions to be effective. Then the child may find a pathway in the social and symbolic space by which he can negotiate a means of satisfying the drive. What is at issue in the case of the Borderline is the failure to establish this limit to the Superego. It is as if the distancing of the Superego-established by the articulation of parental demands within the ideals of the culture and blaming parental lack on causes about which the child can do nothing - had failed. As if the drive energy had remained captive to the very demands of parental dissatisfaction to which it was a response. Hence the paranoid position of the Borderline, in whose case the energy of the drive works for the Other, diverted by demands that, because they are censored and not represented, assume the force of nonnegotiable imperatives within language. 
This failed articulation of the Superego within cultural ideals renders impossible both the construction of the seduction fantasy as a solution and the distancing of the exigencies of the Superego. The seduction fantasy binds the energy of the drive by attaching it to the production of the Ego as an imaginary object of the Other's desire. The production of the Ego as an ideal object cannot take place outside of the parameters provided by the ideals of a given culture. Indeed, it is the values, ideals and norms of a given culture that define the contours of the ideal Ego as well as the very modalities of the forms in which seduction can take place. We have only to imagine the traveler in the foreign land who finds himself, as it were, hors texte, unaware of the cultural codes that organize the frame through which he might enter into a rapport with the other. It is only on the condition of being articulated with social ideals that the Ego can perform its function of tempering the demands for jouissance by the imaginary Other of the Superego. The construction of the seduction marks and signs the passage to the social bond. It is indeed the conditions of the rapport with others in the social bond that the seduction puts into place, manages and organizes, as if it had escaped from the influence of the Superego and were at the beck and call of the drive it triggers.

It is at the Oedipal moment, during what we call the phallic phase, that this passage to the social bond takes place with the construction of the Ego that constitutes itself as an object worthy of love and recognition by others in the social bond. The failure of this passage is illustrated by what psychiatry identifies as "identification or narcissistic troubles" in the case of the Borderline.

The Borderline then lives the impossibility of constructing a fantasy of seduction, of imagining himself as a possible object of the Other's desire. Thus he remains grappling with the anarchic work of the drive, which is unbound, unbridled, and non-structured by an ideal Ego articulated with the ideals of the culture. It is this very impossibility, this failure of the constitution of the ideal Ego that the acting out will stage in a repetitive fashion. The acting out is the spontaneous staging of the return of the censored which acts upon the body in a form and in a mode that interpellates the Other held responsible for the failure. It brings the censored back to the social space by requiring a response from the Other, the one responsible for the limitation and management of the jouissance that acts upon the being. In this respect, it is truly inscribed in the same logic as the solution of the seduction, all while ceaselessly inscribing its failure. The failure of this attempt at reparation is both inevitable and structural. It is as if the 
Borderline experiences, perhaps too early in life, that the limit produced by language in the social bond is insufficient and cannot possibly manage the unbound drive and the return of the censored; As if he found himself in the position inevitably occupied by the adolescent, facing the insufficiency and groundlessness of solutions proposed by the parent and by society-a moment of "crisis" wherein the adolescent is faced with the possibility of leaving behind the demands of the parental superego in order to try to give a negotiable form, within the social bond, to the drive and to the mental representation that the drive invests in the fantasy.

Whereas the hysteric is able to face the failure of the seduction fantasy which, in the imaginary, made him the object of the Other's desire, the Borderline had never been able to construct such an illusion. The problem of the hysteric stems rather from his difficulty in taking leave of the imaginary, and in assuming and managing this failure as something inevitable and structural. As if the failure of seduction could be put down to his insufficiency as an object of the Other's desire, allowing the hysteric to maintain the illusion of an object at once possible, adequate, sufficient and satisfying vis-à-vis the drive of desire, deferring as such the moment in which he would assume his lack-of-being. Whereas in the case of the hysteric we see a discourse of grievance, of accusations leveled at the other, the Borderline stages, acts out, plays in the real at once the desperate appeal to the Other as well as the demonstration of the Other's insufficiency, of his incapacity, if not his bad faith. The acting out brings the obscene back into the social bond, which it breaks by inscribing in it the censored, in forms that the social space neither authorizes nor is able to manage, soliciting or implying the other, who must bear the responsibility of triggering the drive as well as its treatment. The acting out is not an act of the subject. Rather, it is a spontaneous response of the being to something that remains censored and not represented in the signifier. The acting out attempts to inscribe on the body or in the reality of the relationship with the other a limit to the work of the unbound drive. But because its means of inscription rests outside of the signifier, it only ends up staging its inevitable failure. The acting out is a waste of time. It calls for an external limit from the social bond to that which can only be managed from the inside. As if the Borderline stubbornly demanded from the other (who is there in the social bond) a signifier that would give voice to the very censored (thing) that acts upon him, a signifier that would arrive at the place where only a signifier produced by the subject himself could possibly be effective. The act articulates the real in the symbolic by giving it a meaningful form, one recognizable and negotiable by the 
other. The acting out stages in the social space the work of the drive in the return of the censored, but in an encrypted language whose decoding would be the task of the other. It thus includes and maintains an impossible demand addressed to an imaginary Other who would be necessarily powerless.

\section{The Management of the Return of the Censored}

The problem of the Borderline is reminiscent of the point of view according to which the subject himself manages that which remains untreated and untreatable in him, within the limits established by the social bond. Willy Apollon reminds us that "society is structured around representations censored as obscene, and by representations promoted as ideal, as values” (Séminaire Capitalisme. Science et psychanalyse, 18 mars, 2009). "Societies," he adds, have "various spaces that serve as outlets for the censored. Art provides an acceptable place for that which has been rejected, religion controls the expression of the censored, and science produces various mental representations" (Sessions de formation, I 3 mars 2009). Indeed, science attempts to extend the field of mental representations in hopes of being able to name-and thus predict and control-the real.

The censored mental representations the subject grapples with in his fantasy, to which are fastened his drive and his desire, require a means of expression and a signification that can only be singular and produced by the subject himself. If, for example, art, religion or science provide openings or possible sites for the expression of the censored, they in no way exempt the subject from having to create a particular mode of expression for that which inhabits him, in a form that would be negotiable, if not presentable in social space.

The mental representations issuing from primordial experiences - hose which detach the living from his biological destiny in order to subject him to the effects of the signifier and create the drive-remain inaccessible, impenetrable and completely singular, since they bear witness to the particular mode of the subject's constitution. The hallucinatory experiences that evoke the effraction and the object of the Other of the Voice, mental representations which furnish the material for the primal fantasy, these can only ever be calculated, deduced from the repetitive logic the fantasy organizes in the diverse manifestations of the subject's life: his acts, his choices, his decisions, positions and symptoms. Likewise, the contours of the impossible object at the heart of the subject's quest are all but calculable. Thus it is profoundly impossible 
to manage this singular mental universe (in which, moreover, language has carved up that which should have remained unrepresented in language and in the social bond) within the means offered by culture and society. Each subject, who is absolutely alone in this respect, finds himself obliged to create his own solution, in the same way that he finds himself constrained to confront, alone, his own death. That which triggers the drive comes from inside, Freud tells us, and thus the subject can neither flee nor escape its hold. As the result of hallucinatory experiences and representations, it cannot be satisfied by any object whatsoever from the realm of perceptible reality. The task I designated above as the articulation of the body with language, of the real of the drive with the symbolic, depends upon the creativity and the freedom of the subject, who alone can work to carve out a place and give a presence and visibility in social space to that which is excluded from it as possible. A production of the subject that would be signed with the singular letters of its desire, and which inscribes a mark, punctures a hole in common sense by reintroducing the censored into it in a form that remains within the limits of the negotiable in language and the social bond. Here lies the entire problem: how to represent the subject and its desire in a space which, by definition, excludes it? Lacan admirably evokes this impasse which each of us must resolve: "As language becomes more functional, it becomes improper for speech, and as it becomes too particular to us, it loses its function as language" ("Function and field of speech and language," Ecrits 85).

Such an act or word from the subject, tying, for him, the real to the symbolic, arrives at the place where, most of the time, the symptom arises. Indeed, it is most often a symptom that will take the place of the production of the subject of the unconscious; a symptom which, presentable in the social bond, reintroduces the censored in a disguised form, one acceptable within society's values. The symptom, whether in the form of a sickness, a job, a professional choice, or a spouse and kids, links the energy of the drive to an object. A compromise solution dear to the neurotic, the symptom allows him to avoid the consequences he would inevitably provoke by assuming the expression of the unconscious desire, severing the subject from the social bond.

The act of the subject and the practice of the signifier within speech exist in another field than that of the symptom. Essentially, they subvert the social bond. True speech, what Lacan calls "full speech," necessarily presupposes taking leave of the discourse that structures the social bond. Speech evokes the mental representation of the fantasy, the hallucinated 
object, that which is unverifiable by the other, but especially that which cannot be experienced by the other. Speech both conveys and relies upon experience, on the truth of the subject. Thus it always engages the body, jouissance, desire, anguish. This practice of the signifier, which is that of the analytic experience but not limited to it, has structuring effects in the body, if and only if the signifier comes to evoke the presence of the desiring body in language, if the signifier, as Willy Apollon puts it, is "chosen by the letter of the body." Speech then becomes an act, an act signed by the subject who creates meaning out of the un-presentable he carries within himself. Speech works to find signifiers for what is not said, for that which the subject does not know before having said it; for the truth of which he was ignorant, for "that" ("ça") which he did not know himself to be. The act of speaking, then, the practice of the signifier, is a way out for the censored that it transforms and represents.

Thus the creative act is fundamentally an act produced alone. As long as creation is marred by an address which defines its possible contours and prohibitions, it remains enclosed within the norms of the social bond, where it can only come to grief. It is the subject that creates. Never the Ego. The domains of art, science, religion and politics provide us with decisive examples in this regard. Science advances when it is the scientist as a subject who creates, when mental representations drive his quest. In these moments, the creativity of the scientist far surpasses the field of the perceptible, anticipating that which will be possible in the real only several decades later. The situation is similar in art, where we perhaps need to distinguish the practitioner of art from the creator who is the subject that creates and signs a work that will henceforth be recognizable precisely because of this signature, and which can only come from the object within him that searches for its form of expression. It is therefore not obvious that a subject speaks or produces an act. 


\section{Works Cited}

Apollon, Willy. Capitalisme, science et psychanalyse: les enjeux éthiques de l'impasse créée par la mondialisation, Séminaire public donné à Québec et à Montréal, 2008-2009, inédit.

---. Métapsychologie, Session de formation du 13 mars 2009, Québec, inédit.

Lacan, Jacques. "Function and field of speech and language." Écrits: A Selection. W.W. Norton, 1977. 30-113.

---. "On a question preliminary to any possible treatment of psychosis." Écrits: A Selection. W.W. Norton, 1977. 179-225.

---. "The signification of the phallus." Écrits: A Selection. W.W. Norton, 1977. 28I-29I. 